\title{
Pathway for the elimination of melamine in lactating dairy cows
}

\author{
P. Sun, ${ }^{\star}$ J. Q. Wang, ${ }^{\star 1}$ J. S. Shen, ${ }^{\star}$ and H. Y. Wei† \\ *State Key Laboratory of Animal Nutrition, Institute of Animal Science, Chinese Academy of Agricultural Sciences, Beijing, 100193, P. R. China \\ †Ministry of Agricultural Milk and Dairy Inspection and Supervision Center (Beijing), Beijing, 100193, P. R. China
}

\begin{abstract}
Melamine might be degraded into cyanuric acid and some other analogs by the rumen microorganism. Thus, the metabolism of melamine in ruminants may be different from that in monogastric animals. The objective of this study was to investigate the pathway for the elimination of melamine in lactating dairy cows. Four late-lactation dairy cows (body weight $=524 \pm 17 \mathrm{~kg}$, days in milk $=265 \pm 14 \mathrm{~d}$ ) fitted with ruminal cannulas were dosed with melamine (purity $\geq 99.5 \%$ ) at $800 \mathrm{mg} / \mathrm{d}$ per cow that divided into 2 equal daily doses. The trial lasted for $20 \mathrm{~d}$ (13-d preliminary period, followed by a 7-d sample-collecting period). The method of liquid chromatography and tandem mass spectrometry was used to determine melamine and cyanuric acid contents simultaneously. Before the trial started, no melamine or cyanuric acid was detected in samples of total mixed ration, milk, plasma, urine, and feces. The melamine concentration in rumen fluid $(\mathrm{Y}, \mathrm{mg} / \mathrm{L})$ decreased exponentially after the morning feeding (X, h) $\left(\mathrm{Y}=3.85591 \mathrm{e}^{-\mathrm{X} / 9.25674}+1.35924, \mathrm{R}^{2}=0.99\right)$, but no cyanuric acid was detected. Plasma melamine concentration $(0.296 \pm 0.014 \mathrm{mg} / \mathrm{L})$ was relatively stable in the 3 different sampling times. The percentages of melamine excreted through milk, urine, and feces were $0.48 \pm 0.06,44.07 \pm 10.79$ and $10.98 \pm 3.88 \%$, respectively. It could be inferred that $44.47 \pm 7.98 \%$ of ingested melamine was degraded in the rumen, because cyanuric acid was detected in plasma, urine, and feces on the condition that no melamine was contained in the total mixed ration fed to the dairy cows. The results of the present study implied that the elimination pathway of melamine in lactating dairy cows was different from that in monogastric animals. A high percentage of melamine was degraded into cyanuric acid gradually by rumen microorganisms. Most ingested melamine was excreted in urine and feces, which are the main elimination pathways for melamine in lactating dairy cows.
\end{abstract}

Received March 22, 2011.

Accepted September 23, 2011

${ }^{1}$ Corresponding author: jqwangcaas@gmail.com
Key words: melamine, elimination pathway, cyanuric acid, dairy cow

\section{INTRODUCTION}

Melamine (1,3,5-triazine-2,4,6-triamine), a relatively stable substance, is mainly utilized for the production of melamine resins and plastics (Subrayan and Rasmussen, 1995; Weil and Choudhary, 1995). Animal studies have indicated that melamine does not undergo obvious metabolism and, for the most part, is excreted by the kidneys (Reimschuessel et al., 2008; Hau et al., 2009; Lv et al., 2010). Mast et al. (1983) reported that $90 \%$ of ingested melamine could be excreted by kidneys within 24 h. Baynes et al. (2008) demonstrated that tissue distribution of melamine may be limited to the total body water and significant tissue binding is unlikely . All of these studies were focused on monogastric animals. Jutzi et al. (1982) and Shelton et al. (1997) proved that melamine could be metabolized by bacteria to form cyanuric acid, which can be further metabolized in the body. Being uniquely different from monogastric animals, ruminants have a rumen, and large amounts of microorganisms including bacteria, fungi, and protozoa live in the rumen. It is reasonable to speculate that melamine might be degraded by rumen microorganisms, resulting in the production of its analogs, such as ammelide, ammeline, and cyanuric acid. Consequently, the metabolism of melamine in ruminants might be different from that in monogastric animals. Previous studies demonstrated that melamine could be slowly hydrolyzed in the rumen, but it was not a good NPN source for ruminants (Newton and Utley, 1978). To our knowledge, no biotransformation of melamine has been reported in ruminants until now.

Cruywagen et al. (2009) reported that melamine can be transferred into milk from feed and melamine excretion via milk accounted for about $2 \%$ of the ingested melamine $(17.1 \mathrm{~g} / \mathrm{d}$ per cow). Our previous study demonstrated that the mean melamine excretion via milk accounted for about 0.66 to $0.95 \%$ when dairy cows ingested relatively low amounts of melamine (90-450 $\mathrm{mg} / \mathrm{d}$ per cow; Shen et al., 2010), lower than the value obtained by Cruywagen et al. (2009). According to 
the determination of melamine in urine, Cruywagen et al. (2009) believed that urine was the major route of melamine excretion in lactating dairy cows. To date, whether melamine could be degraded by rumen microorganisms and how much melamine could be degraded in the rumen or excreted through urine and feces are still unknown. Therefore, the present study was conducted to test the hypothesis that melamine could be degraded to form its analogs by rumen microorganisms and discover their elimination pathway in lactating dairy cows.

\section{MATERIALS AND METHODS}

\section{Animals, Diets, and Experimental Design}

Animals used in this study were cared for and handled following the guidelines established by the Institute of Animal Science, Chinese Academy of Agricultural Sciences, Beijing, China. The health of cows was monitored continuously before and during the experimental period.

Four Chinese Holstein cows $(\mathrm{BW}=524 \pm 17 \mathrm{~kg}$, $\mathrm{DIM}=265 \pm 14 \mathrm{~d}$, milk yield $=13.2 \pm 2.16 \mathrm{~kg})$ that had been fitted previously with ruminal cannulas (10cm center diameter; Bar Diamond Inc., Parma, ID) were dosed with melamine (Beijing Chemical Reagents Ltd., Beijing, China; purity $\geq 99.5 \%$ ) at $800 \mathrm{mg} / \mathrm{d}$ per cow, divided into 2 equal daily doses. Cows were housed in individual tie-stalls fitted with rubber mats and had continuous access to water from drinking cups. Ingredients and the chemical composition of the basal diet consumed by all of the cows are presented in Table 1. Diets were offered as TMR for approximately $5 \%$ feed refusal, fed in equal amounts at 0700 and $1900 \mathrm{~h}$. Individual cow feed intake was measured and recorded once daily. Cows were milked twice daily at 0600 and $1800 \mathrm{~h}$, and individual milk yield was recorded for each milking.

Before the trial started, all cows received diets without melamine or cyanuric acid for $3 \mathrm{~d}$. Feed, milk, urine, feces, and blood samples were collected and analyzed for melamine and cyanuric acid to determine the background concentration. No melamine or cyanuric acid was detected in any of the samples before the trial. The trial lasted for $20 \mathrm{~d}$ (13-d preliminary period, followed by a 7 -d sample-collecting period). Every day, before each feeding, cows were allowed to consume $400 \mathrm{mg}$ of melamine mixed with about $35 \mathrm{~g}$ of concentrate. Thereafter, the TMR was fed. On d 14, 4 cows were moved to metabolism stalls to ensure the complete collection and separation of feces and urine. Feed intake and total output of feces, urine, and milk were measured daily for $3 \mathrm{~d}$. Urine, feces, milk, feed, and orts were sampled daily, refrigerated $\left(4^{\circ} \mathrm{C}\right)$, and composited for the $3-\mathrm{d}$ experiment. Cows remained in those stalls for $3 \mathrm{~d}$, and then moved back to the tie-stalls for the remainder of the period. On d 17 and 18, blood samples (10 mL) were taken from the tail artery using Vacutainer tubes (BD Biosciences, San Jose, CA) containing heparinanticoagulant at 0 (pre-dose), 4 and $8 \mathrm{~h}$ after morning feeding. Blood samples were centrifuged at 3,000 $\times g$ for $15 \mathrm{~min}$ at $4^{\circ} \mathrm{C}$, and the separated plasma was stored at $-20^{\circ} \mathrm{C}$ for melamine and cyanuric acid analysis. On d 19 and 20, rumen fluid samples (via the cannula) were collected at $1,2,4,8$, and $12 \mathrm{~h}$ after morning feeding. Rumen fluids were taken from multiple sites in the rumen, composited, and strained through 4 layers of cheesecloth. The $\mathrm{pH}$ of the strained ruminal filtrate was measured immediately, using a pocket-sized $\mathrm{pH}$ meter (Hanna Instruments, Woonsocket, RI). Fifty milliliters of rumen filtrate collected at each sampling time was stored at $-20^{\circ} \mathrm{C}$ for analysis of melamine and cyanuric acid.

Table 1. Ingredients and chemical composition of the basal diets (DM basis)

\begin{tabular}{lc}
\hline Item & Concentration \\
\hline Ingredient (\% of DM) & \\
Corn silage & 28.00 \\
Chinese wild rye & 14.00 \\
Brewers grain & 7.50 \\
Bean curd residue & 6.00 \\
Corn & 19.0 \\
Cottonseed meal & 6.50 \\
Wheat bran & 3.70 \\
Soybean meal & 1.75 \\
Peanut meal & 2.40 \\
Yeast powder & 2.75 \\
Scrap tankage & 3.10 \\
Corn embryo cake & 1.85 \\
Salt & 0.50 \\
Premix ${ }^{1}$ & 0.50 \\
Sodium bicarbonate & 0.90 \\
Calcium monohydrogen phosphate & 0.40 \\
Limestone & 0.75 \\
Calcium carbonate precipitated light & 0.40 \\
Chemical composition ${ }^{3} \%$ of DM) & \\
NE ${ }^{3}$ (MJ/kg of DM) & 6.23 \\
DM (\%) & 40.63 \\
CP & 15.92 \\
Ether extract & 4.69 \\
NDF & 41.30 \\
ADF & 22.97 \\
Ca & 0.72 \\
P & 0.36 \\
\hline
\end{tabular}

${ }^{1}$ Contained (per kilogram of DM) a minimum of 250,000 IU of vitamin A; $65,000 \mathrm{IU}$ of vitamin D; 2,100 IU of vitamin E; $400 \mathrm{mg}$ of Fe; 540 $\mathrm{mg}$ of $\mathrm{Cu} ; 2,100 \mathrm{mg}$ of $\mathrm{Zn} ; 560 \mathrm{mg}$ of $\mathrm{Mn} ; 15 \mathrm{mg}$ of Se; $35 \mathrm{mg}$ of I; and $68 \mathrm{mg}$ of $\mathrm{Co}$.

${ }^{2}$ Analyzed value.

${ }^{3}$ The $\mathrm{NE}_{\mathrm{L}}$ values (Mcal $/ \mathrm{kg}$ of $\mathrm{DM}$ ) used for alfalfa hay, Chinese wild rye, corn silage, corn, wheat bran, soybean meal, cottonseed meal, rapeseed meal, corn meal, and soybean oil were 1.19, 1.12, 1.45, 1.91, $1.61,2.38,1.71,1.86,1.80$, and 5.65 , respectively (China Standard $\mathrm{NY} / \mathrm{t} 34,2004)$. 
Samples of the diet, orts, and feces were dried at $60^{\circ} \mathrm{C}$ for $48 \mathrm{~h}$ in a forced-air oven, and then ground through a 2-mm screen in a Cyclotec 1093 sample mill (Foss Analytical AB, Höganäs, Sweden), composited on an equal-weight basis, reground through a 1-mm screen, and stored in a sealed plastic bag until analyzed for melamine and cyanuric acid. The dried and ground samples were composited in proportion to the amount of DM each day.

\section{Determination of Melamine in Diets, Milk, Plasma, Rumen Fluid, Urine, and Feces}

Melamine and cyanuric acid in samples of feed, milk, plasma, rumen fluid, urine, and feces were analyzed simultaneously using liquid chromatography/tandem mass spectrometry (LC-MS/MS), following Filigenzi et al. (2008) with some modifications. Standards of melamine and cyanuric acid were purchased from Sigma Chemical Co. (St. Louis, MO; purity at 99\%). ${ }^{15} \mathrm{~N}_{3}$-Melamine and ${ }^{13} \mathrm{C}_{3}$-cyanuric acid, purchased from ICON Services (Summit, NJ), served as internal standards. Briefly, $100 \mathrm{mg}$ of melamine and $100 \mathrm{mg}$ of cyanuric acid were dissolved in $0.2 \%$ formic acid solution in $100 \mathrm{~mL}$ volumetric flasks; thus, a melamine and cyanuric acid solution at $1.0 \mathrm{mg} / \mathrm{mL}$ of melamine and cyanuric acid was prepared as a stock standard solution. Then, the melamine and cyanuric acid stock solution was further diluted with $0.2 \%$ formic acid in water and the standard working mixture solutions ranging from 0.5 to $10 \mu \mathrm{g} / \mathrm{mL}$ were obtained. The standard stock solution and the working mixture solutions remained stable at $4^{\circ} \mathrm{C}$ for $6 \mathrm{mo}$ and $2 \mathrm{wk}$, respectively. Thereafter, the working mixture solutions were diluted with acetonitrile and melamine and cyanuric acid calibration standards were prepared at 2.5, 5, 10, 25, and $50 \mathrm{ng} /$ $\mathrm{mL}$, which contained $25 \mathrm{ng}$ of ${ }^{15} \mathrm{~N}_{3}$-melamine $/ \mathrm{mL}$ and $50 \mathrm{ng}$ of ${ }^{13} \mathrm{C}_{3}$-cyanuric acid $/ \mathrm{mL}$.

The samples of diets and feces were dried and finely ground so they would pass through a 40-mesh sieve and then a $1-\mathrm{g}$ portion was dissolved in $20 \mathrm{~mL}$ of a $2 \%$ mixture solution of formate, acetonitrile, and de-ionized water $(70: 20: 10, \mathrm{vol} / \mathrm{vol} / \mathrm{vol})$ in a $50-\mathrm{mL}$ centrifuge tube. Then, $80 \mu \mathrm{L}$ of standard melamine solution and $240 \mu \mathrm{L}$ of standard cyanuric acid solution were added before vibrating for $5 \mathrm{~min}$. The mixed solution was extracted ultrasonically for $15 \mathrm{~min}$, followed by vortexing for $10 \mathrm{~min}$, and then centrifuged at $10,000 \times g$ for $10 \mathrm{~min}$. The resultant supernatant from each sample was loaded onto a reversed-phase column (Symmetry C18, $5 \mu \mathrm{m}, 4.6 \times 150 \mathrm{~mm}$; Waters Chromatography Ireland Ltd., Dublin, Ireland) at a flow rate of $1 \mathrm{~mL} /$ min, which was washed with $4 \%$ formic acid solution and acetonitrile and eluted with ammonium acetate in water using a gradient elution program while being dried under a stream of nitrogen at $60^{\circ} \mathrm{C}$. The dried extract was dissolved in $2 \mathrm{~mL}$ of acetonitrile solution and vortexed for $1 \mathrm{~min}$ before filtered through a 0.45 $\mu \mathrm{m}$ filter (Millipore Corp., Milford, MA). Aliquots of raw milk $(2 \mathrm{~mL})$ and plasma $(0.5 \mathrm{~mL})$ were processed similarly as described by Lv et al. (2010). Extraction and purification of rumen fluid and urine samples were performed as follows: after vortexing, $1 \mathrm{~mL}$ of liquid was added in a 10-mL centrifuge tube, and then melamine and cyanuric acid mixture solution together with acetonitrile was also added. After being vortexed for $5 \mathrm{~min}$, the mixed solution was centrifuged at 10,000 $\times g$ for 10 min. The supernatant was filtered through a $0.22-\mu \mathrm{m}$ filter for LC-MS/MS.

The detection limits for melamine and cyanuric acid was 0.05 and $0.2 \mathrm{mg} / \mathrm{kg}$ for feed samples, 0.02 and 0.05 $\mathrm{mg} / \mathrm{kg}$ for milk samples, and 0.05 and $0.025 \mathrm{mg} / \mathrm{kg}$ for tissue samples, respectively.

\section{Statistical Analysis}

Time evolution was modeled by regression of rumen fluid melamine concentration $(\mathrm{mg} / \mathrm{kg})$ over time $(\mathrm{h})$. Plasma melamine or cyanuric acid concentrations were analyzed using the GLM procedures of the SAS system (version 9.0; SAS Institute Inc., Cary, NC). Differences among treatments were analyzed with the Tukey multiple range test. $P$-values $\leq 0.05$ were considered statistically significant. The percentage of melamine excreted through milk, urine, or feces was calculated as the ratio between the mean output of melamine in milk, urine, or feces and the melamine administered per day, separately for each cow.

\section{RESULTS AND DISCUSSION}

The average pattern of melamine concentration in rumen fluid $(\mathrm{Y}, \mathrm{mg} / \mathrm{kg})$ was represented by the following exponential decreasing function (Figure 1):

$$
\mathrm{Y}=3.85591 \exp (-\mathrm{h} / 9.25674)+1.35924\left(\mathrm{R}^{2}=0.99\right)
$$

From the average pattern of melamine concentration in rumen fluid, the maximum concentration occurred in the samples collected at the first collection after morning feeding. Rumen fluid melamine concentration decreased exponentially over time (h). Rumen fluid melamine concentration collected at $12 \mathrm{~h}(2.45 \pm 0.54$ $\mathrm{mg} / \mathrm{L}$ ) after morning feeding was about one-half of the value obtained at $1 \mathrm{~h}(4.86 \pm 0.48 \mathrm{mg} / \mathrm{L})$ after morning feeding. Cruywagen et al. (2009) reported that it took $6 \mathrm{~d}$ or longer before the milk was completely free of melamine after removing melamine from the feed and 


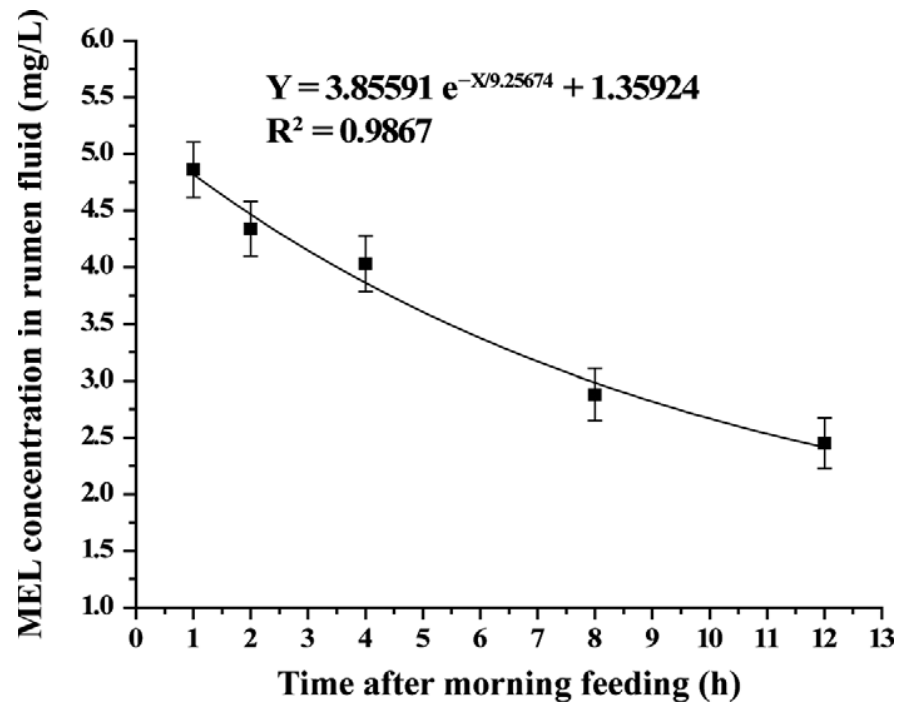

Figure 1. Average decrease pattern of melamine (MEL) in rumen fluid after the morning feeding. Data are presented as means \pm standard deviations $(\mathrm{n}=4)$.

they demonstrated that it was probably related to the passage rate of melamine-containing feed from the rumen, which has been proved in the present study.

It has been documented that the degradative pathway of melamine seemed to be hydrolytic and proceeded by 3 successive deaminations to cyanuric acid by microorganisms, such as Pseudomonas and Klebsiella terragena, in vitro (Jutzi et al., 1982; Shelton et al., 1997); then, the cyanuric acid was further metabolized because of its lower dissociation constant (pKa; Battaglia et al., 2010). However, monogastric animal studies have indicated that melamine does not undergo obvious metabolism in the body, but, for the most part, is excreted by the kidneys (Lipschitz and Stokey, 1945; Mast et al., 1983). Given the large amounts of microorganisms (bacteria, fungi, and protozoa), including Pseudomonas aeruginosa, living in the rumen (Duncan et al., 1999), it can be deduced that melamine could also be degraded gradually by rumen microorganisms to produce its analogs, such as ammelide, ammeline, and cyanuric acid, which has been confirmed by the fact that cyanuric acid was detected in plasma, urine, and feces in the present study. The concentrations of cyanuric acid in plasma, urine, and feces were $0.120 \pm$ $0.012(\mathrm{SEM}) \mathrm{mg} / \mathrm{L}, 0.88 \pm 0.23(\mathrm{SD}) \mathrm{mg} / \mathrm{L}$, and 1.88 $\pm 1.92(\mathrm{SD}) \mathrm{mg} / \mathrm{kg}$ (air-dry basis), respectively. However, no cyanuric acid was detected in rumen fluid in this study. This phenomenon might be because (1) only limited melamine was transformed into cyanuric acid; (2) cyanuric acid was metabolized further by rumen microorganisms; (3) the continuous outflow of rumen digesta (including melamine and cyanuric acid) to the lower digestive tract; or (4) melamine and cyanuric acid might also be absorbed by the rumen wall. All of these reasons lead to the lower cyanuric acid concentration in rumen fluid below the quantification limit $(<0.02 \mathrm{mg} /$ $\mathrm{kg}$ ). However, concentrations of cyanuric acid were relatively higher after the rumen digesta passed through the omasum, as part of the nutrients from the digestible feed and a large amount of water were absorbed in the omasum.

Patterns of melamine and cyanuric acid concentrations in plasma are shown in Figure 2. Plasma melamine concentration was relatively stable at the 3 different sampling times. The total mean plasma melamine concentration was $0.296 \pm 0.014 \mathrm{mg} / \mathrm{L}$. The concentration of melamine in milk and urine were $0.285 \pm$ 0.051 and $31.77 \pm 11.17 \mathrm{mg} / \mathrm{L}$, respectively. Melamine concentration in milk was similar to that in plasma but melamine concentration in urine was about 100-fold higher than that in plasma. This may be explained by the fact that melamine concentration was condensed during the course of urine formation because more than $90 \%$ of the water had been absorbed, resulting in the higher concentration of melamine in the urine. Because blood was collected on d 17 and 18, during which the melamine was fed to the dairy cows continuously, the concentrations of melamine and cyanuric acid for time 0 in Figure 2 reflected the residues in the plasma after the last feeding. It was revealed that melamine and cyanuric acid, which is transferred from blood, could be detected in milk for several days even after melamine was removed from the diet. Similar results were obtained in our previous study (Shen et al., 2010; Sun

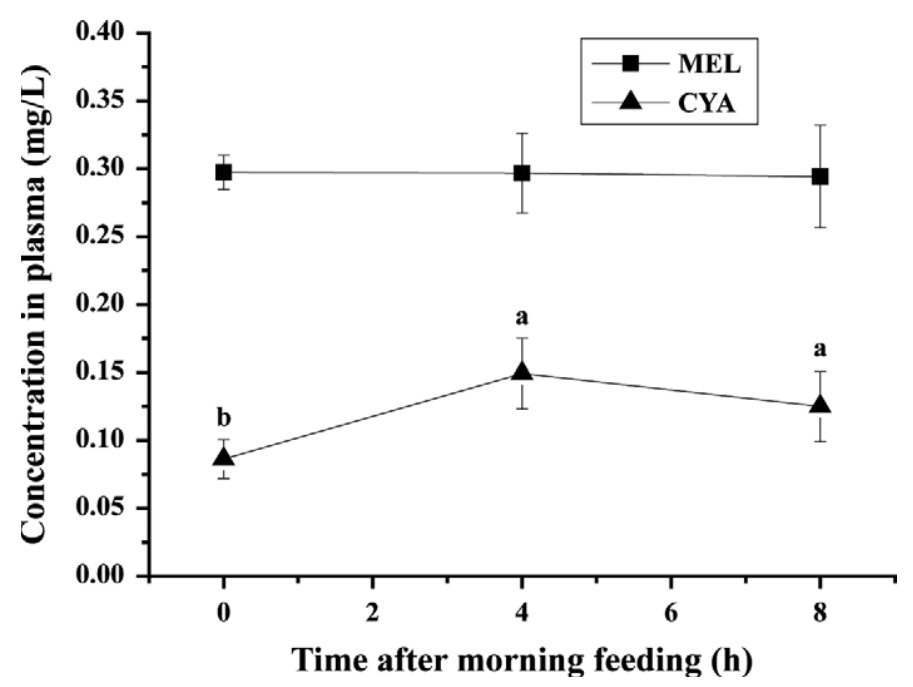

Figure 2. Plasma melamine (MEL) or cyanuric acid (CYA) concentrations at different sampling times. Data are presented as means \pm standard deviations $(\mathrm{n}=4)$. Different letters $(\mathrm{a}$ and $\mathrm{b})$ indicate a significant difference $(P<0.05)$. 
Table 2. Metabolism parameter of melamine in dairy cows

\begin{tabular}{|c|c|c|c|c|c|}
\hline Parameter & Cow 1 & Cow 2 & Cow 3 & Cow 4 & Mean \pm SD \\
\hline Melamine intake $(\mathrm{mg} / \mathrm{d})$ & 800 & 800 & 800 & 800 & \\
\hline Milk yield $(\mathrm{kg} / \mathrm{d})$ & 14.93 & 10.77 & 14.47 & 14.40 & $13.64 \pm 1.93$ \\
\hline Feces output (kg/d; dry basis) & 5.88 & 6.11 & 5.58 & 6.30 & $5.97 \pm 0.31$ \\
\hline Urine output $(\mathrm{kg} / \mathrm{d})$ & 7.49 & 12.62 & 10.61 & 16.81 & $11.88 \pm 3.90$ \\
\hline \multicolumn{6}{|l|}{ Melamine concentration $(\mathrm{mg} / \mathrm{kg})$} \\
\hline Milk & 0.26 & 0.34 & 0.31 & 0.23 & $0.29 \pm 0.05$ \\
\hline Feces (dry basis) & 20.50 & 14.26 & 8.28 & 15.50 & $14.63 \pm 5.02$ \\
\hline Urine & 38.54 & 22.39 & 43.97 & 22.18 & $31.77 \pm 11.17$ \\
\hline \multicolumn{6}{|l|}{$\%$ of melamine intake } \\
\hline Milk melamine & 0.47 & 0.46 & 0.56 & 0.42 & $0.48 \pm 0.06$ \\
\hline Feces melamine & 15.05 & 10.88 & 5.78 & 12.21 & $10.98 \pm 3.88$ \\
\hline Urine melamine & 36.09 & 35.31 & 58.31 & 46.59 & $44.07 \pm 10.79$ \\
\hline Others (all transformed) & 48.39 & 53.35 & 35.35 & 40.78 & $44.47 \pm 7.98$ \\
\hline Other transformers or metabolites other than cyanuric acid & 46.89 & 50.83 & 33.18 & 35.45 & $41.59 \pm 8.60$ \\
\hline \multicolumn{6}{|l|}{ Cyanuric acid concentration $(\mathrm{mg} / \mathrm{kg})$} \\
\hline Milk & $\mathrm{ND}^{1}$ & ND & ND & ND & \\
\hline Feces (dry basis) & 0.93 & 0.60 & 1.26 & 4.73 & $1.88 \pm 1.92$ \\
\hline Urine & 0.88 & 1.33 & 1.01 & 0.82 & $0.88 \pm 0.23$ \\
\hline
\end{tabular}

${ }^{1} \mathrm{ND}=$ not detected at the method detection limit of $0.05 \mathrm{mg} / \mathrm{kg}$.

et al., 2011) and other publications (Cruywagen et al., 2009; Battaglia et al., 2010).

After bypassing the rumen, the elimination of melamine in ruminants may be similar to that in monogastric animals. Part of the undegraded melamine passed the rumen and was absorbed into the blood in the following digestion tract. Unabsorbed melamine was excreted through feces. As shown in Table 2, the percentages of melamine excreted through milk, urine, and feces were $0.48 \pm 0.06,10.98 \pm 3.88$, and $44.07 \pm$ $10.79 \%$, respectively, suggesting that no significant tissue binding occurred in the body of ruminants, as observed by other investigators (Mast et al., 1983; Baynes et al., 2008). Simultaneously, it could be inferred that $44.47 \pm 7.98 \%$ of ingested melamine was degraded or absorbed in the rumen, which was partly confirmed by the existence of cyanuric acid in plasma, urine, and feces. Approximately $41.59 \pm 8.60 \%$ of fed melamine might be transformed to other metabolites other than cyanuric acid by subtracting the amounts of melamine in milk, urine, and feces, as well as the amounts of cyanuric acid in milk, urine, and feces from total ingested melamine by mass balance.

In addition, except for the excretion of melamine and its analogs through milk, urine, and feces, sweating is another potential pathway for the excretion of melamine and cyanuric acid. However, the excretion of melamine or cyanuric acid by sweating was ignored in the present study because the trial was conducted in winter (from February to March in northern China) when sweating was little for dairy cows. Further study is still needed for thorough research of the excretion of melamine and its analogs from the sweat glands of dairy cows.

\section{CONCLUSIONS}

The results of the present work indicate that the metabolism of dietary melamine in ruminants is different from that in monogastric animals. With the existence of the rumen, $44.47 \pm 7.98 \%$ of ingested melamine was directly absorbed by the rumen wall or degraded into its analogs (mainly cyanuric acid) gradually by rumen microorganisms. Besides milk, urine and feces were the main pathways for the excretion of melamine in dairy cows, through which more than $50 \%$ of fed melamine was removed from the body.

\section{ACKNOWLEDGMENTS}

This study was financially supported by the Ministry of Agriculture (Beijing, China) and by an earmark fund for the Modern Agro-Industry Technology Research System of the P. R. China (nycytx-04-01).

\section{REFERENCES}

Battaglia, M., C. W. Cruywagen, T. Bertuzzi, A. Gallo, M. Moschini, G. Piva, and F. Masoero. 2010. Transfer of melamine from feed to milk and from milk to cheese and whey in lactating dairy cows fed single oral doses. J. Dairy Sci. 93:5338-5347.

Baynes, R. E., G. Smith, S. E. Mason, E. Barrett, B. M. Barlow, and J. E. Riviere. 2008. Pharmacokinetics of melamine in pigs following intravenous administration. Food Chem. Toxicol. 46:1196-1200.

Cruywagen, C. W., M. A. Stander, M. Adonis, and T. Calitz. 2009. Hot topic: Pathway confirmed for the transmission of melamine from feed to cow's milk. J. Dairy Sci. 92:2046-2050.

Duncan, S. H., C. J. Doherty, J. R. W. Govan, S. Neogrady, P. Galfi, and C. S. Stewart. 1999. Characteristics of sheep-rumen isolates of Pseudomonas aeruginosa inhibitory to the growth of Escherichia coli O157. FEMS Microbiol. Lett. 180:305-310.

Filigenzi, M. S., B. Puschner, L. S. Aston, and R. H. Poppenga. 2008. Diagnostic determination of melamine and related compounds in 
kidney tissue by liquid chromatography/tandem mass spectrometry. J. Agric. Food Chem. 56:7593-7599.

Hau, A. K., T. H. Kwan, and P. K. Li. 2009. Melamine toxicity and the kidney. J. Am. Soc. Nephrol. 20:245-250.

Jutzi, K., A. M. Cook, and R. Hütter. 1982. The degradative pathway of the $s$-trizaine melamine. The steps to ring cleavage. Biochem. J. 208:679-684.

Lipschitz, W. L., and E. Stokey. 1945. The mode of action of three new diuretics: Melamine, adenine and formoguanamine. J. Pharmacol. Exp. Ther. 83:235-249.

Lv, X., J. Wang, L. Wu, J. Qiu, J. Li, Z. Wu, and Y. Qin. 2010. Tissue deposition and residue depletion in lambs exposed to melamine and cyanuric acid-contaminated diets. J. Agric. Food Chem. 58:943-948.

Mast, R. W., A. R. Jeffcoat, B. M. Sadler, R. C. Kraska, and M. A. Friedman. 1983. Metabolism, disposition and excretion of $\left[{ }^{14} \mathrm{C}\right]$ melamine in male Fischer 344 rats. Food Chem. Toxicol. 21:807810.

Newton, G. L., and P. R. Utley. 1978. Melamine as a dietary nitrogen source for ruminants. J. Anim. Sci. 47:1338-1344.

Reimschuessel, R., C. M. Gieseker, R. A. Miller, J. Ward, J. Boehmer, N. Rummel, D. N. Heller, C. Nochetto, G. K. H. de Alwis, N.
Bataller, W. C. Andersen, S. B. Turnipseed, C. M. Karbiwnyk, R. D. Satzger, J. B. Crowe, N. R. Wilber, M. K. Reinhard, J. F. Roberts, and M. R. Witkowski. 2008. Evaluation of the renal effects of experimental feeding of melamine and cyanuric acid to fish and pigs. Am. J. Vet. Res. 69:1217-1228.

Shelton, D. R., J. S. Karns, G. W. McCarty, and D. R. Durham. 1997. Metabolism of melamine by Klebsiella terragena. Appl. Environ. Microbiol. 63:2832-2835.

Shen, J. S., J. Q. Wang, H. Y. Wei, D. P. Bu, P. Sun, and L. Y. Zhou. 2010. Transfer efficiency of melamine from feed to milk in lactating dairy cows fed with different doses of melamine. J. Dairy Sci. 93:2060-2066.

Subrayan, R. P., and P. G. Rasmussen. 1995. An overview of materials composed of carbon and nitrogen. Trends Polym. Sci. (Regul. Ed.) $3: 165-172$.

Sun, P., J. Q. Wang, J. S. Shen, and H. Y. Wei. 2011. Residues of melamine and cyanuric acid in milk and tissues of dairy cows fed different doses of melamine. J. Dairy Sci. 94:3575-3582.

Weil, E. D., and V. Choudhary. 1995. Flame-retarding plastics and elastomers with melamine. J. Fire Sci. 13:104-126. 